LITERATURA 



\title{
¿PUEDE HABLAR EL SUBALTERNO EN LA CUENTÍSTICA CONTEMPORÁNEA DE CUBA?
}

\author{
Markus Ebenhoch
}

\section{(c) ${ }_{\mathrm{EY}} \mathrm{NO} \mathrm{ND}_{\mathrm{ND}}$}

Doi: https://doi.org/10.15517/rfl.v45i2.39069

URL: https://revistas.ucr.ac.cr/index.php/filyling/index 



\title{
¿PUEDE HABLAR EL SUBALTERNO EN LA CUENTÍSTICA CONTEMPORÁNEA DE CUBA?
}

\author{
CAN THE SUBALTERN SPEAK IN CONTEMPORARY \\ CUBAN SHORT STORY?
}

\section{Markus Ebenhoch}

\begin{abstract}
RESUMEN
Después de la caída del muro de Berlín, en Cuba comenzó el así llamado "Período Especial en tiempos de paz". Como consecuencia de los profundos cambios políticos y sociales surgieron en la narrativa cubana de los noventa nuevos discursos postrevolucionarios. En este trabajo se examina la representación del habla subalterna, concretamente el caso de los personajes afectados por la miseria económica, en un corpus de 120 cuentos escritos entre 1990-2000. Partiendo de los conceptos teóricos de Antonio Gramsci y Gayatri Spivak, así como de los temas tratados en el corpus, se presentan y discuten los resultados del análisis narratológico de aquellos 59 cuentos que contienen descripciones de pobreza; además se aborda el estatus del autor cubano, los personajes literarios y el lenguaje utilizado. El análisis de la instancia narrativa resulta asimismo de suma importancia para la cuestión de la articulación subalterna: entre estos 59 cuentos, 29 utilizan instancias narrativas homodiegéticas, de los cuales 18 viven en condiciones miserables. Si bien 23 cuentos se caracterizan por instancias narrativas heterodiegéticas, en solo dos textos los lectores se encuentran frente a una focalización interna que se encuentra dentro de una perspectiva subalterna. Tres de los siete cuentos que oscilan entre instancias narrativas homodiegéticas y heterodiegéticas se construyen con narradores pobres. Palabras clave: Cuento; Cuba; narratología; Spivak; subalternidad.
\end{abstract}

\begin{abstract}
After the fall of the Berlin Wall, the so-called "Special Period in Times of Peace" began in Cuba. As a consequence of the profound political and social changes, new post-revolutionary discourses emerged in Cuban narrative in the 1990s. This paper examines the representation of subaltern speech, especially the case of characters affected by economic misery, in a corpus of 120 short stories written between 1990-2000. Based on the theoretical concepts of Antonio Gramsci and Gayatri Spivak as well as on the themes dealt in the corpus, the results of the narratological analysis of those fifty-nine short stories that contain descriptions of poverty will be presented and discussed; furthermore, the status of the Cuban author, the literary characters and the literary language will be discussed. The analysis of the narrators is of great importance for the question of subaltern articulation: Among these fifty-nine stories are twenty-nine texts that use homodiegetic narrators, eighteen of which live in miserable conditions. Twenty-three short stories are characterized by heterodiegetic narrators, but in just two texts the readers are faced with an internal focalization that is framed within a subaltern perspective. Three of the seven stories that oscillate between homodiegetic and heterodiegetic narrators are built with poor storytellers.
\end{abstract}

Keywords: Short story; Cuba; narratology; Spivak; subalternity.

Dr. Markus Ebenhoch. Profesor auxiliar en el Departamento de Lenguas y Literaturas Románicas. Universidad de Salzburgo. Austria.

Correo electrónico: markus.ebenhoch@sbg.ac.at

Recepción: 12- 09- 18

Aceptación: 14- 01- 19 


\section{La dicotomía entre subalternidad y hegemonía}

Quisiera empezar este trabajo con un breve resumen de la argumentación de Gayatri Spivak en torno al concepto de "subalternidad", teniendo en cuenta sobre todo su famoso ensayo "Can the Subaltern speak?" (1988). Spivak recurre al término "subalterno", elaborado por el comunista italiano Antonio Gramsci en el contexto del marxismo europeo en las primeras décadas del siglo XX. Un aspecto tentador del concepto de subalternidad de Gramsci es su carácter multidimensional y relacional: multidimensional porque no limita la subalternidad a factores económicos y políticos, sino que considera también aspectos socioculturales. Según Gramsci, la hegemonía se impone igualmente por vías institucionales en el ámbito socio-cultural, por ejemplo, mediante la educación o la religión. Relacional, dado que la subalternidad existe porque la hegemonía lo crea. Por un lado, los subalternos dependen del poder hegemónico; por otro lado, pueden socavar la hegemonía y transformar su estatus para lograr hegemonía ellos mismos (Gramsci, 1975, pp. 2277-2294; Barfuss y Jehle, 2014; para la recepción de Gramsci en Cuba véase Acanda et al., 1997; Chanan, 2001 y Martínez Heredia, 2001). Spivak adapta varias reflexiones de Gramsci a la discusión postcolonial, tales como la idea de que el poder hegemónico se impone a través de distintas instituciones en la sociedad civil, la figura del "intelectual orgánico" o el carácter dicotómico-relacional de los conceptos hegemonía y subalternidad. Spivak pretende que los subalternos sí puedan hablar, sin embargo, su argumentación es propuesta por la vía negativa, puesto que muestra los obstáculos para la articulación del sujeto subalterno. En su ensayo "Can the Subaltern speak?", analiza los discursos bienintencionados de Gilles Deleuze y Michel Foucault que intentan dar voz a los sujetos subalternos, pero, según Spivak, estos no llegan a tener en cuenta las dos dimensiones del acto de representar: darstellen y vertreten en la terminología de Karl Marx. Spivak insiste en que estas dos dimensiones están interrelacionadas, lo que significa que cualquier acto de representación en el ámbito del arte, de la economía o de la antropología (darstellen) es a su vez una representación política (vertreten). Así que, si los intelectuales hegemónicos dan voz a los subalternos postcoloniales en una representación artística, los estarían representando al mismo tiempo políticamente, es decir, estarían apropiándose de sus voces. Spivak detecta esta estructura también en dos ejemplos provenientes del contexto colonial de la India: el suicidio de mujeres en un rito funerario hindú y el suicidio de una joven india en la lucha por la independencia de Gran Bretaña. En ambos casos, las voces de las mujeres son silenciadas porque sus contemporáneos no las escucharon, no entendieron las intenciones de estos actos corporales. En vista de dichos ejemplos históricos, Spivak concluye su ensayo "Can the Subaltern speak?" con la famosa frase que plantea que la mujer subalterna no puede hablar (Spivak, 1988, p. 308). La argumentación de Spivak fue discutida intensamente en las últimas décadas en varias disciplinas y hasta ella misma relativizó su provocativa tesis (Spivak, 1999, p. 308). Sin embargo, la cuestión de si el sujeto subalterno puede hablar sigue teniendo validez, dado que los actos de habla no se limitan a la expresión subalterna, sino que esta expresión también debe ser escuchada por los que forman parte de la hegemonía.

Entonces habría que preguntarse, ¿cómo se desmonta la dicotomía entre hegemonía y subalternidad? En la obra de Spivak encontramos varias propuestas para que los subalternos entren en la esfera de la hegemonía. Quisiera mencionar aquí solo dos y discutir una tercera que, a mi parecer, se ajustan acertadamente al contexto cubano: 
1) La resistencia subalterna, por ejemplo, en forma de rebeliones, puede socavar la hegemonía. Aunque Spivak rechaza la subalternidad como estatus ontológico esencialista, sí acepta la idea de una identidad subalterna colectiva como "esencialismo estratégico" en el ámbito de la política (Ashcroft, Griffiths y Tiffin, 1998, pp. 77-80; Spivak, 1990, p. 109; Spivak, 1996, p. 306). La Revolución cubana es sin duda un proceso político por el cual, a partir de 1959, los antiguos sectores subalternos, por lo menos en parte, subieron al poder.

2) Según Spivak, los intelectuales bienintencionados tendrán que abandonar la tentación de hablar por los subalternos, olvidar ciertos privilegios y entrar en contacto directo con estos sujetos (Spivak, 1990, pp. 56-57; Spivak, 1996, pp. 269-271). En la Cuba revolucionaria se rechazó la idea tradicional del intelectual burgués y se propagó la figura gramsciana del "intelectual orgánico", enraizado en la cultura popular y que desde esta perspectiva realiza su labor intelectual.

3) Spivak opina que los textos literarios operan como lugares retóricos alternativos donde se pueden articular relatos de subalternos. Esta tesis la desarrolla sobre todo en su ensayo "A Literary Representation of The Subaltern: A Woman's Text From the Third World" (Spivak, 1987, pp. 241-268), la defiende en algunas entrevistas (por ejemplo: Spivak, 1990, p. 56) e incluso la lleva a la práctica a través de su labor como traductora de la autora bengalí Mahasweta Devi, quien retrata en sus cuentos y novelas distintas formas de violencia, represión y resistencia, enfocando la situación de las mujeres en la India postcolonial (Castro Varela y Dhawan, 2015, pp. 156-163; Morton, 2003, pp. 55, 124).

Para entender esta sugerente tesis hay que relacionar varios argumentos aducidos por Spivak. El primer aspecto plantea la relación entre la realidad y la ficcionalidad.

\footnotetext{
Those who read or write literature can claim as little of subaltern status as those who read or write history. The difference is that the subaltern as object is supposed to be imagined in one case and real in another. I am suggesting that it is a bit of both in both cases. The writer acknowledges this by claiming to do research (my fiction is also historical). The historian might acknowledge this by looking at the mechanics of representation (my history is also fictive) (Spivak, 1987, p. 244).
}

En la postrera parte de la cita, Spivak cuestiona la clasificación que ubica a la realidad como dominio exclusivo de la historiografía y lo imaginado como elemento únicamente representado en el ámbito de la literatura. Para ella, la distinción entre lo real y lo imaginado es "a difference in degree rather than in kind" (Spivak, 1987, p. 243). Entre los filólogos e historiadores se discute esta temática con conceptos como effet de réel (Barthes, 1968), emplotment (White, 1973) o discours y généalogie (Foucault, 1971 y 1994). Un segundo aspecto es mencionado en la frase inicial de la cita, cuando Spivak constata que ni los lectores ni los autores de textos literarios e historiográficos poseen un estatus subalterno. Esto es de suma importancia, puesto que los textos literarios no constituyen un lugar de articulación "genuina" de una voz subalterna, aunque en la historia de la literatura haya habido numerosos escritores que altercaron el discurso hegemónico existente de su época. Incluso en el caso del género "testimonio" para el cual se reclamó alguna vez tal estatus, podemos notar que los autores o los editores de dichos textos modifican la articulación subalterna y la adaptan hasta cierto punto a una estética conforme al mercado. Con frecuencia actúan como "ventrílocuos" (Beverley, 1999, p. 135) al presentar a los protagonistas como voces legítimas y haciendo creer al lector que ellos mismos, o sea los autores y editores, respectivamente, no están presentes en los actos de habla. Una de las consecuencias de esta técnica literaria para el mercado del libro internacional es 
que el lector del norte toma con frecuencia al escritor del sur como representante de las voces subalternas o hasta identifica la voz autorial con voces subalternas reales.

Spivak reiteradamente reprende este tipo de identificación simple, no obstante, sostiene que en los textos literarios se pueden articular relatos subalternos. Estos textos -y aquí tocamos un tercer aspecto de la argumentación de Spivak- no necesariamente serían relatos de resistencia subversiva, ya que en ese caso tematizarían igualmente fracasos, problemas de articulación o hasta silencios por parte de los sujetos subalternos. Los textos ayudarían, cuarto aspecto, a la construcción de relaciones éticas entre lectores y subalternos, las cuales se forman a través de dichos relatos. En las palabras de Spivak, y retomando el vínculo entre historia y literatura, se expresa así:

\begin{abstract}
Fiction and its pedagogy can [...] perform the ideological mobilization of a moral economy that a mere benevolent tracing of the historical antecedents of the speaker might not be able to. The two must go together as each other's "interruption," for the burden of proof lies upon historical research. It is to belabor the obvious to say the structures of logical and legal-model scholarly demonstrations alone cannot bring about counter-hegemonic ideological production (Spivak, 1987, p. 256).
\end{abstract}

Cuando Spivak pondera "la movilización ideológica de una economía moral” así como la "producción ideológica contra-hegemónica" evoca una de las funciones tradicionales de la literatura: sensibilizar al lector, función que para Spivak posee un pronunciado carácter político. El quinto y último aspecto refiere a que los intelectuales -y podemos incluir en este grupo a los escritores-, teniendo en cuenta su posición privilegiada y la diferencia existente entre su posición y el sujeto subalterno, deben representar, analizar y dedicarse a los relatos subalternos. Asumirían de cierta manera el papel de la ninfa Eco de la mitología griega, condenada a repetir lo que fue dicho anteriormente (Nandi, 2007, pp. 251-256).

\title{
2. ¿Temas subalternos en la cuentística cubana finisecular?
}

Ahora bien, ante el panorama de una Cuba en pleno fervor revolucionario, en los años inmediatamente posteriores a 1959, donde los antiguos sectores subalternos entraron parcialmente en la esfera hegemónica y se fomentaron aquellos tipos de literatura como el género "testimonio" para dar "voz a los sin voz", se podría preguntar: ¿De qué manera atañe la Cuba de los años noventa a esta situación histórica? ¿Por qué se aplican los conceptos "subalternidad" y "hegemonía" a una sociedad que a inicios de los años noventa ya había atravesado un proceso político de más de 30 años que redujo y hasta eliminó algunas de las formas de subalternidad más obvias (la pobreza, el analfabetismo, etc.), un proceso que dio poder hegemónico a sectores antes subalternos? Para responder a estas interrogantes me gustaría recurrir al cuento "Relato de hombre al margen" del escritor cubano Alberto Garrido. Este texto forma parte del volumen de cuentos El muro de las lamentaciones, con el cual Garrido ganó el prestigioso Premio Casa de las Américas en 1999. El yo-narrador es un escritor que tiene problemas económicos, pero sufre también por la miseria cotidiana ajena, la que describe en sus propios textos literarios. En sus paseos por la ciudad de La Habana se topa con distintos marginados como prostitutas, mendigos o un vendedor ambulante ilegal. El encuentro nocturno con una mendiga que está sentada en un portal lo retrata con las siguientes palabras:

\footnotetext{
Tiene los ojos cerrados pero no duerme; los mantiene apretados para no recordar mi silueta mientras pide algún dinero. [...] [T]engo frente a mí a la mujer, no a la evocada en el vaso de alcohol como se evocan los demonios, sino a la que extiende una mano apenas silueteada en lo oscuro sobre el instante de la piedad y el terror de ser humillada. Adivino en los bolsillos (Garrido, 1999b, p. 87).
} 
La percepción de la mendiga por parte del protagonista provoca un breve proceso de reflexión y termina con un acto de misericordia silencioso. Este tipo de choques y personajes como mendigos y desamparados son característicos de una estética de la pobreza. La singularidad del encuentro citado es su ubicación temporal y espacial, dado que la Cuba socialista se vanagloria de la erradicación total de la pobreza existente en la época prerrevolucionaria. Durante décadas ningún cubano tuvo que pedir limosnas ni vivir en la calle. Solo a partir de los años 90 aparecen de nuevo mendigos en las zonas urbanas. El yo-narrador del cuento "Relato de hombre al margen" es consciente de esta singularidad, lo que se nota en sus reflexiones después de observar a un viejo y un muchacho que están echados en el suelo cerca de los grandes hoteles turísticos (significativamente estos dos subalternos están posicionados enfrente de un edificio que simboliza la hegemonía económica). El yo-narrador está seguro de haber visto a estos dos personajes antes, probablemente en una pintura expresionista:

Pero lo peor no es la repetición del arte en la vida, la copia infame que le hace la vida simplificando los mismos cuerpos largos y resignados. Lo peor es haber creído con ingenuidad que esas caras se habían perdido en los cuadros tras la primavera del mil novecientos cuatro, sin suponer que surgirían famélicos y silenciosos en los sumideros, funerarias, calles y parques (Garrido, 1999b, p. 101).

Este texto no es una excepción en mi corpus de 120 cuentos escritos por narradores cubanos entre 1990 y 20001. Casi la mitad de los cuentos contiene descripciones de esta "nueva pobreza" que se distingue de la pobreza prerrevolucionaria. En comparación con la literatura revolucionaria de los años 1960 y 1970 que habló de la pobreza en términos de una memoria dolorosa de la dictadura de Fulgencio Batista, la literatura postrevolucionaria conoce la pobreza como fenómeno actual. En los cuentos, esta se manifiesta mediante la escasez de ingresos y dinero, los problemas de nutrición, salud, alojamiento e infraestructura pública y por medio de las fisuras sociales entre extranjeros y cubanos. Raras veces la miseria económica surge como fenómeno aislado, sino que aparece entrelazada con la etnicidad de los pobres y las estrategias para combatir la pobreza. Entre las estrategias legales podemos nombrar el trabajo voluntario, las alternativas agrícolas, la solidaridad y la emigración. Sin embargo, las estrategias más empleadas son de carácter ilegal, por ejemplo, el trabajo informal, las actividades en el mercado negro, la corrupción, el robo, la pordiosería, la prostitución y la huida de Cuba (Ebenhoch, 2013).

Antes de relacionar la pobreza con el concepto spivakiano de la subalternidad, quisiera mencionar brevemente los otros temas y motivos tratados en la cuentística cubana de la última década del siglo XX. Dado que el panorama se presenta bastante amplio, me concentraré en algunos bloques temáticos centrales que, por un lado, indican el diálogo con la cuentística

He dado importancia al criterio de que dichos narradores vivieron por lo menos cierto tiempo en la isla caribeña durante la última década del siglo XX. Por lo tanto, los escritores de mi corpus conocieron la miseria cotidiana de primera mano, igual que el protagonista-narrador del cuento "Relato de hombre al margen". La mayoría de los autores de los cuentos analizados vivieron y viven en la isla; sin embargo, se han incluido también en este estudio a escritores que durante los noventa se decidieron por el exilio y otros que oscilan entre Cuba y el exterior. Muchos de los cuentos recibieron prestigiosos premios internacionales, por ejemplo, el Premio Juan Rulfo (Paris) y el Premio Casa de las Américas (La Habana) o premios nacionales como el de La Gaceta de Cuba. El equilibrio con respecto al lugar de la publicación es otro criterio para delimitar el corpus, por tal motivo los textos escogidos provienen asimismo de cinco antologías cubanas y cinco antologías publicadas fuera de la isla, respectivamente (Véase anexo). 
anterior y su renovación, y por otro, implican una ruptura radical al tocar temas que antes constituían tabúes. Los temas y motivos que con más frecuencia aparecen en mi corpus son la sexualidad en sus distintas formas, el turismo incluyendo el jineterismo, forma particular de prostitución que se realiza entre un/a cubano/a y un/a turista extranjero/a, la religión que resurge en los noventa con nuevo brío después del decretado ateísmo socialista, el arte y la subcultura urbana, la vida escolar y estudiantil en parte conflictiva, la participación cubana en la Guerra de Angola así como la violencia familiar, social, criminal y estatal. Este panorama temático coincide en gran parte con los resultados de los análisis comparativos de Behar (2009), Fornet (2006), Martín Sevillano (2004), Rubio Cuevas (2001), Whitfield (2008) y Uxó (2010), que llegan a identificar los mismos o parecidos bloques temáticos de la narrativa cubana de los noventa, aunque todos con un corpus parcialmente distinto que puede incluir hasta novelas. Partiendo de esta base temática, se podría aplicar el concepto "subalterno", por ejemplo, a las constelaciones jerárquicas entre los soldados subordinados y los oficiales durante la Guerra de Angola o al enfrentamiento entre los "rockeros" o "frikis" marginados y los representantes del poder estatal que intentan reprimir ciertas formas de la subcultura urbana. Sin embargo, se limitará la conceptualización de Gayatri Spivak sobre el habla subalterna a aquellos 59 cuentos que contienen representaciones literarias de la pobreza. Obviamente, la miseria económica es solo una de las diversas formas de ser subalterno, pero por razones de operabilidad me decidí por este enfoque, teniendo en cuenta que la pobreza está intrínsecamente entrelazada con otras formas de subalternidad como la cuestión racial o de género.

\section{3. ¿Voces subalternas en la cuentística cubana?}

Si uno discute la posibilidad del habla subalterna en el marco de la narrativa, hay que considerar en primer lugar las implicaciones de la ficcionalidad y de la instancia narrativa. Los mundos ficcionales muestran a menudo coincidencias significativas con el mundo real, sin embargo, el carácter ficcional les otorga autonomía. El lector no debe identificar las voces ficcionales de los sujetos subalternos con actos de habla verdaderos. Las representaciones literarias del habla subalterna son, en el mejor de los casos, meros ecos o un simulacrum de una articulación subalterna real en el marco de la ficción. Apoyándose en la vida real, los escritores crean mundos ficcionales, imágenes, personajes o sueños que, por su parte, pueden influir en la percepción de la realidad cotidiana. Desde la teoría poética antigua, comenzando por Platón y Aristóteles, los filósofos subrayan que la literatura muestra distintas posibilidades de cómo se puede pensar y hablar y, en el contexto de la distinción entre mimesis y diégesis, identifican la instancia intermediadora como rasgo característico de los textos narrativos. Retornando a la cuestión del habla subalterna es necesario realzar que las instancias narrativas determinan la representación de los subalternos porque o simplemente los describen o los dejan hablar a través del discurso del personaje o se presentan ellas mismas como sujetos subalternos. Siempre y cuando los subalternos tomen la palabra en forma de personaje o instancia narrativa, y si el receptor de esta habla se sumerge en el mundo ficcional subalterno y lo entiende, existe la posibilidad de que los sujetos subalternos sí puedan hablar en el marco de la ficción.

Para indagar la posibilidad del habla subalterna en los textos narrativos, se debería comenzar por examinar el lugar de la instancia narrativa, dado que esto indicaría si el narrador forma parte del mundo ficcional presentado o no. Si se relaciona además el análisis de la instancia narrativa con el análisis de los personajes, posiblemente podamos identificar voces 
subalternas en los textos. Antes de presentar y discutir los resultados del análisis cuantitativo de los 59 cuentos con descripciones de pobreza cotidiana, quisiera ilustrar este aspecto central de la cuestión del habla subalterna a través del cuento "Greenpeace" de Eduardo del Llano. En el marco del relato, el defensor de oficio Nicanor O'Donnell entra en la celda donde los tres amigos de apodo "Gravilla", "Sangre’e mono" y "Negroemierda" están encerrados con la intención de escuchar su historia "como se lo contarían a un amigo". ¿La reacción? "Ninguno habló durante un par de minutos" (Llano, 2002, p. 107). Solo después de este silencio, Gravilla reacciona mostrándose indignado por ser tratados como delincuentes y quejándose, pues alude que el juicio contra ellos será una "farsa, como siempre" (Llano, 2002, p. 108), independientemente de cómo O`Donnell construya la defensa. El defensor de oficio aclara a los tres detenidos de qué delitos se les acusa:

Yo lo único que sé es que los acusan de atentado al patrimonio cultural, sabotaje, distribución de propaganda enemiga, intento de sacrificio ilegal de ganado, agresión física al administrador de una granja estatal y usurpación de funciones, para empezar. Tienen que convencerme de que no son culpables, para que yo pueda convencer al juez (Llano, 2002, p. 108).

Aquí es donde surgen las primeras dificultades en el diálogo entre subalternos y representantes del poder hegemónico. Los acusados no entienden el término "usurpación de funciones". Después de la explicación de O’Donnell y la repetida petición de explicarle la historia desde la perspectiva de ellos, su solicitud es escuchada y el defensor de oficio queda fascinado por la narración por los presos:

Gravilla no se mostró muy convencido de que valiera la pena, pero Sangre'e mono y Negroemierda estaban locos por reconstruirlo todo de nuevo, con la elocuencia que el oficial instructor les fragmentó y piloteó en el interrogatorio. Y yo, que había aceptado el caso de puro oficio y a desgana, comencé a descubrirme fascinado con el relato (Llano, 2002, p. 108).

En esta cita, las observaciones sobre la posibilidad de una articulación subalterna son particularmente interesantes. Gravilla aparentemente ya ha abjurado la creencia en la habilidad subalterna de hablar. No cree que su historia será escuchada correctamente, pero sus amigos Sangre'e mono y Negroemierda todavía guardan esta esperanza. La parte central de la cita es relevante para nuestra cuestión. La instancia narrativa del marco del relato comenta aquí la elocuencia de Sangre'e mono y Negroemierda, los dos narradores del relato enmarcado que previamente fue "fragmentada" y "piloteada" por el instructor durante el interrogatorio. Aunque no podamos deducir de qué manera este proceso tuvo lugar y qué consecuencias causó (¿Las instrucciones ayudan a los presos en prisión preventiva? ¿El instructor redujo las declaraciones de los acusados a lo que él consideró esencial? ¿Se perdió la perspectiva subalterna?), sí se puede constatar que el discurso subalterno fue deformado y adaptado al discurso hegemónico.

La estructura narrativa y la elaboración estilística del cuento "Greenpeace" subrayan las dificultades del habla subalterna. En la trama externa, el defensor de oficio Nicanor O’Donnell no solo es protagonista, sino que también es instancia narrativa autodiegética. Los lectores echan un primer vistazo a los marginales Gravilla, Sangre'e mono y Negroemierda mediante la perspectiva de O'Donnell; los comentarios sobre ellos igualmente provienen de este representante del poder hegemónico. Así que, en la primera parte del cuento, la voz subalterna queda reducida al discurso directo de los tres detenidos. La fascinación de O’Donnell por su historia, mencionada en la cita anterior, y la referencia explícita a Sangre'e mono y Negroemierda como protagonistas-narradores del relato enmarcado crean una expectativa 
específica: la trama interna, además de ser fascinante, debe ser leída según sus implicaciones penales, por ende, O’Donnell, el destinatario de esta narración al nivel metadiegético, representa al "oyente ideal" (Kayser, 1971, p. 202), porque tiene que autentificar la increíble historia de los acusados y presentar su versión ante el tribunal de justicia. Inesperadamente, empero, Eduardo del Llano se decide en contra de una instancia narrativa homodiegética en el relato enmarcado.

La historia sobre la fundación de un comando ecológico por Gravilla, Sangre’e mono y Negroemierda, la descripción de la implementación práctica de sus ideales en La Habana, así como el retrato de su miseria económica son presentadas por un clásico narrador omnisciente que no pertenece al mundo subalterno retratado. A nivel estilístico se nota fácilmente la discrepancia entre el discurso educado del narrador y el lenguaje coloquial lleno de vulgarismos del discurso directo de los tres protagonistas ambientalistas. De vez en cuando el narrador heterodiegético comenta con cierta arrogancia o con sutil ironía las actividades de los tres protagonistas que quieren salvar al planeta de la catástrofe ecológica en un contexto en que todo el mundo tiene otros problemas, por lo que se les considera como locos.

Al final de la narración, el cuento "Greenpeace" se vuelve a centrar en la imagen de la celda con la cual se inició la trama externa. El defensor de oficio Nicanor O’Donnell demuestra ser un oyente atento a la articulación subalterna, o sea, al relato enmarcado enunciado por Sangre'e mono y Negroemierda; no obstante, al salir de la celda duda que su versión de la historia fuere aceptada por el tribunal de justicia, es decir, por el poder hegemónico. Para resumir, el cuento de Eduardo del Llano retrata jocosamente cómo los subalternos piensan, actúan y hablan, e incluso muestra la comunicación conflictiva a través de los representantes de la hegemonía sin llegar a otorgarles el poder de la palabra en forma de instancia narrativa.

Ahora quisiera presentar y discutir los resultados del análisis cuantitativo para responder a las siguientes preguntas: ¿existen narradores subalternos en la cuentística cubana contemporánea?, ¿de qué manera se expresan?, ¿se pueden identificar tipos narrativos predilectos para la expresión subalterna?

De los 59 cuentos que contienen descripciones de pobreza, casi la mitad se caracteriza por una instancia narrativa homodiegética. En estos casos la gran mayoría de los narradores actúa también como protagonista de sus relatos, situación que según Gérard Genette indica instancias narrativas autodiegéticas. De este primer grupo de 29 cuentos con instancias homodiegéticas, un total de 20 textos utiliza la focalización interna fija ${ }^{2}$, dos la focalización interna múltiple ${ }^{3}$, un cuento se caracteriza por una focalización interna variable ${ }^{4}$, otro cuento por la transformación de un narrador en primera persona singular a un narrador en primera persona plural $^{5}$, dos textos tienen la forma de relato epistolar ${ }^{6}$ y otros tres textos muestran una estructura que quisiera denominar "diálogo con un interlocutor callado". En esta última estructura narratológica el lector se ve enfrontado a un narrador autodiegético que sostiene un diálogo con su interlocutor. Sin embargo, las palabras de dicho interlocutor solo son

2 Abreu Morales, 1997; Bahr, 2000; Díaz Llanillo, 2000; Díaz Mantilla, 1993; Gala, 2004; Garrido, 1999b; Garrido, 2002; Garrido, 2004; Gutiérrez, 2001a; Gutiérrez, 2001b; Mejides, 2004; Menéndez, 2002; Pérez, 2003; Ponte, 2002; Quintana Veiga, 2006; Ribeaux, 1997; Sánchez, 2004a; Santiesteban, 2002; Torralbas Caurel, 1993; Vega, 2002.

3 Cano, 2002; Mitrani, 2002.

4 Menéndez, 1993.

5 Díaz-Pimienta, 2002.

$6 \quad$ Alonso, 1997a; Gala, 1997.

Doi: https://doi.org/10.15517/rfl.v45i2.39069 / URL: https://revistas.ucr.ac.cr/index.php/filyling/index 
reproducidas por el protagonista, ya que nunca se lee su propio discurso (en el capítulo 4 se ofrecerá un análisis estilístico de "Clemencia bajo el sol" de Adelaida Fernández de Juan, un texto que pertenece a este último grupo de cuentos) ${ }^{7}$.

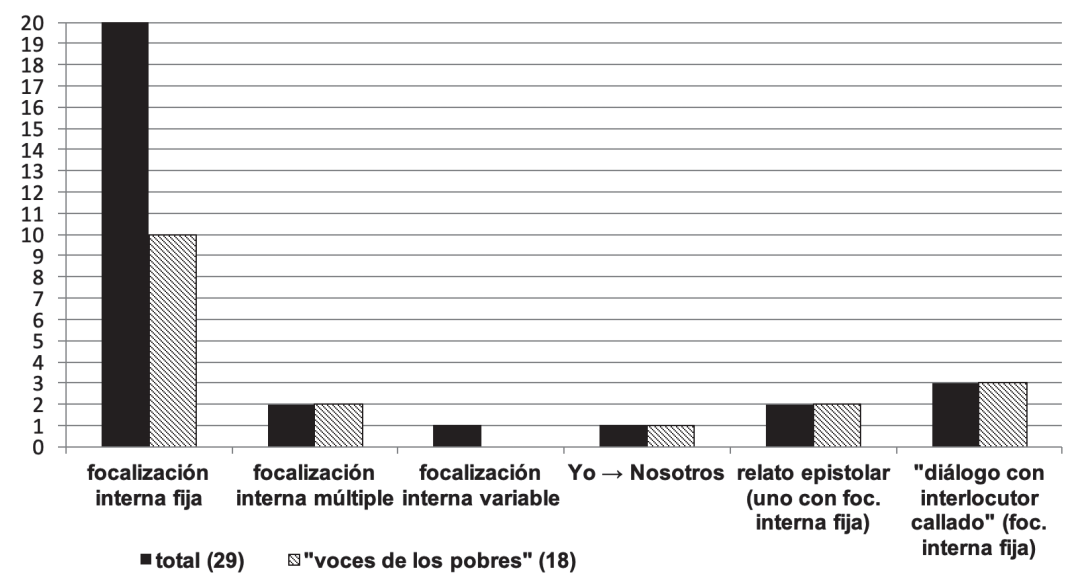

Figura 1. Instancias homodiegéticas Fuente: Elaboración propia.

De los 29 cuentos con instancias homodiegéticas, en 18 casos un personaje pobre toma la función del yo-narrador. Pese a ello, las vidas miserables se distinguen bastante: en cuatro cuentos "jineteras" y "jineteros" describen sus éxitos y fracasos con la clientela internacional"; en tres textos estamos ante narradores infantiles y juveniles ${ }^{9}$; en dos casos los escritores no solo retratan sus propias penurias, sino que describen también a mendigos y prostitutas en su entorno vital $^{10}$; en otros dos textos las instancias narrativas son amas de casa ${ }^{11}$; y en cada uno de los siete cuentos restantes el narrador es estudiante ${ }^{12}$, profesora universitaria ${ }^{13}$, pasajero de autobús ${ }^{14}$, médico $^{15}$, pescador $^{16}$, vendedora ambulante ${ }^{17}$ y matarife ilegal ${ }^{18}$, respectivamente. Esta enumeración de narradores pobres ilustra que la nueva pobreza en la Cuba del Período Especial es un fenómeno que abarca a toda la sociedad, ya que afecta igualmente a personas procedentes de círculos tradicionalmente pudientes (profesores universitarios o médicos) como también a personas de estratos socio-económicos más bajos (mendigos o vendedores ambulantes).

En estos 18 cuentos con instancias narrativas autodiegéticas, los narradores operan en calidad de voces de los pobres y pueden ofrecer al lector miradas desgarradoras acerca del

7 Fernández de Juan, 2002; Sánchez, 2002; Valdés, 2002.

8 Cano, 2002; Garrido, 2002; Mitrani, 2002; Torralbas Caurel, 1993.

9 Díaz Mantilla, 1993; Gala, 2004; Valdés, 2002.

10 Garrido, 1999b; Gutiérrez, 2001b.

11 Díaz Llanillo, 2000; Gala, 1997.

12 Pérez, 2003.

13 Alonso, 1997a.

14 Díaz-Pimienta, 2002.

15 Alonso, 1997a.

16 Gutiérrez, 2001a.

17 Fernández de Juan, 2002.

18 Santiesteban, 2002. 
mundo de la marginalidad. ¿Por qué los yo-narradores parecen estar predestinados a expresar el habla subalterna en el marco de la cuentística? Aquí intervienen varios factores: la instancia narrativa autodiegética es una estructura narrativa típica del género "cuento" (Kayser, 1971, p. 203); el yo-narrador dispone de una perspectiva limitada de los mundos ficcionales y responde así a una característica fundamental del género: la condensación; los cuentos no intentan explicar el mundo entero, sino más bien ofrecen instantáneas de sucesos diversos; el yo-narrador organiza los mundos ficcionales de manera diferente porque carece de omnisciencia, forma parte del mundo creado y testifica lo narrado; además, los textos con un yo-narrador imitan la percepción humana de la realidad (Huertas Uhagón, 1993, pp. 33 y 59). La analogía estructural entre esta constelación narrativa y la experiencia vital humana contiene una oferta de identificación o empatía para los lectores, lo que no se debe infravalorar, especialmente en el contexto de la pobreza, puesto que cada uno tiene de antemano ya ciertas ideas y actitudes éticas asociadas con ella. En el "desplazamiento" que se realiza durante el acto de la lectura, el lector toma el lugar del yo-narrador y mira la pobreza desde esta perspectiva. Sin embargo, reducir la afinidad por los pobres al concepto de identificación sería insuficiente. Patrick Greaney (2008, p. XVIII) argumenta en su estudio Untimely Beggar: Poverty and Power from Baudelaire to Benjamin que no siempre se realiza una identificación a nivel textual o que tal identificación puede anularse en el transcurso del relato hasta convertirse en rechazo.

Quisiera retornar a los resultados del análisis narratológico cuantitativo. En comparación con los cuentos que se caracterizan por una instancia narrativa homodiegética, en los 23 cuentos que tienen instancias narrativas heterodiegéticas ${ }^{19}$, las voces de los subalternos solo pueden tomar la forma de discurso de personaje; no obstante, al utilizar una focalización interna fija, los autores podrían por lo menos proporcionar la perspectiva de los pobres respecto a su entorno vital. Esta opción se aprecia únicamente en dos textos ${ }^{20}$.

Aparte de los 29 cuentos con instancias narrativas homodiegéticas y de los 23 cuentos con instancias narrativas heterodiegéticas, encontramos también siete cuentos que oscilan entre estos dos tipos ${ }^{21}$, de los cuales tres tienen narradores que viven en penuria ${ }^{22}$. La característica común de estos siete textos es la fragmentación de la instancia narrativa (ya vista líneas arriba en el ejemplo "Greenpeace"), una característica que encontramos en otros cinco cuentos $^{23}$ del primer grupo con instancias narrativas homodiegéticas. Siete de estos doce cuentos con instancias narrativas fragmentadas presentan narradores que viven en condiciones de pobreza ${ }^{24}$. Si uno compara estos datos (7 de 12 cuentos, 58\%) con los cuentos que dan la voz narrativa a los pobres y que aplican una focalización interna fija ( $14^{25}$ de 24 cuentos,

19 Alonso, 1997b; Arango, 2004; Arzola, 1993; Arzola, 1997; Arzola, 2000; Bobes, 2000; Collazo, 1996; Garrandés, 1997; Garrido Rodríguez, 1993; Guerra Naranjo, 2002a; Haug, 2003; Jesús, 2002; Llano, 2004; López Sacha, 2002; Padura, 1996; Palacio Rame, 1993; Perdomo, 1997; Portela, 1993; Robles, 2006; Rodríguez, 2006; Valle, 2004; Valle Ojeda, 1993; Venero, 2003.

20 Alonso, 1997b; Valle, 2004.

21 Bobes, 1995; Garrido, 1999a; Guerra Naranjo, 2002b; Guerra Naranjo, 2002c; Guerra Naranjo 2002d; Llano, 2002; Vega Serova, 1998.

22 Garrido, 1999a; Guerra Naranjo, 2002b; Vega Serova, 1998.

23 Alonso, 1997a; Cano, 2002; Díaz-Pimienta, 2002; Menéndez, 1993; Mitrani, 2002.

24 Alonso, 1997a; Cano, 2002; Díaz-Pimienta, 2002; Garrido, 1999a; Guerra Naranjo, 2002b; Mitrani, 2002; Vega Serova, 1998.

25 Díaz Llanillo, 2000; Díaz Mantilla, 1993; Fernández de Juan, 2002; Gala, 1997; Gala, 2004; Garrido, 
58\%), llama la atención que los cuentos con instancias narrativas fragmentadas e instancias narrativas uniformes son proporcionales.

Me gustaría situar brevemente este análisis en un contexto más amplio. Daniel Noemi Voionmaa subraya en su estudio Estética de la pobreza en la literatura latinoamericana (2003) el carácter postmoderno de la novelística contemporánea en Hispanoamérica al mostrar contundentemente la fragmentación del tiempo narrado, de la focalización, de la instancia narrativa y de los cuerpos de los pobres, la cual causaría que los pobres se resistieran a la representación. Estos viven en zonas marginales de difícil acceso, sus cuerpos tienen rasgos animales, la noche y la suciedad oscurecen la mirada hacia ellos y sus voces son fragmentadas y relatadas por instancias narrativas que no se ven afectadas por la miseria. Según Noemi Voionmaa (2003, p. 52), "la fragmentación borra la posibilidad de una voz autorial dominante, hegemónica" e impide la interpretación de que los pobres hoy en día pueden hablar con una voz uniforme y coherente. Noemi Voionmaa opina también que la fragmentación narrativa corresponde a la fragmentación real del mundo y esta se opone a una perspectiva uniforme de la globalización (Noemi Voionmaa, 2003, pp. 48-56, 131-135, 166-188 y 221-222). Aunque concuerdo en muchos aspectos con su argumentación, el resultado de mi análisis narratológico contradice una de sus tesis centrales. Como acabamos de ver, en la cuentística cubana finisecular se utilizan tanto las instancias narrativas uniformes como las instancias narrativas fragmentadas para dar voz a los pobres. De tal manera, la fragmentación no es la única técnica narrativa para representar el habla subalterna.

\section{4. ¿Existe un lenguaje subalterno en la cuentística cubana?}

La renovación estilística de la narrativa cubana bajo el signo del posmodernismo literario ya ha sido largamente comentada por los estudios publicados en los últimos años. Una de las características principales de esta nueva manera de narrar es la imitación del discurso oral de los marginados. Para Sonia Behar (2009, p. 35) "[1]a crisis y el desencanto popular producen un relajamiento en el lenguaje que refleja el nuevo modus vivendi, la nueva realidad circundante. Éstos sólo pueden ser expuestos a plenitud en la literatura del momento a través de un lenguaje provocador, subversivo y transgresor". Este lenguaje retoma elementos del argot popular, vulgarismos, coloquialismos, una sintaxis que se aparta de la norma lingüística establecida y una ortografía que imita hasta dialectos locales (sobre todo el habanero). Con este lenguaje agresivo, los autores transgreden las normas tradicionales (el discurso culto, académico, revolucionario), protestan contra el statu quo de la sociedad cubana, pronuncian lo prohibido, "otorgan a las situaciones narradas un sello de autenticidad" y así "la narración se convierte en una fuente fidedigna de información" (Behar, 2009, p. 61). Behar incluso presupone una función catártica de los textos para el lector reprimido (Behar, 2009, pp. 35, 53, 60-65 y 143). Aunque Behar desarrolla su argumentación sobre una selección específica de autores que suelen ser asociados con la corriente tremendista y sucio-realista (Pedro Juan Gutiérrez, Ángel Santiesteban, Jorge Alberto Aguiar Díaz), varias de sus observaciones pueden

1999b; Garrido, 2002; Gutiérrez, 2001a; Gutiérrez, 2001b; Pérez, 2003; Sánchez, 2002; Santiesteban, 2002; Torralbas Caurel, 1993; Valdés, 2002. 
ser aplicadas a un corpus mucho más vasto, lo que quisiera ilustrar a través del análisis de tres pasajes del cuento "Clemencia bajo el sol"26 de Adelaida Fernández de Juan:

¿Y qué me dice de la carne enlatada? No, no voy a bajar la voz, yo no tengo pelos en la lengua ni horchata en las venas, mucha hambre que matamos con la carne rusa y con las manzanas de pomo. Es verdad que sabían a rayo encendido, pero ¿ahora qué? Ahora ni trueno ni rayo ni la madre que los parió (Fernández de Juan, 2002, p. 82).

Esta cita da muestras del fuerte carácter de la protagonista Cuqui, una mujer segura de sí misma, quien se encuentra ante un tribunal de justicia en La Habana acusada por homicidio. Con facilidad combina los giros "no tener pelos en la lengua" y "ni horchata en las venas" para realzar que no tiene la intención de bajar su voz ante el juez. Estos giros, al igual que el coloquialismo "saber a rayo", proceden del inventario de imágenes de la realidad cotidiana. Se utiliza una serie de figuras retóricas para recrear el discurso oral: el anacoluto, el énfasis, dos paralelismos y el zeugma en "yo no tengo pelos en la lengua ni horchata en las venas, mucha hambre que matamos con la carne rusa y con las manzanas de pomo"; la elipsis "Ahora ni trueno ni rayo ni la madre"; la geminación "No, no"; la interrogación retórica "pero ¿ahora qué?”; la repetición de palabra "¿ahora qué? Ahora”.

Estos tropos y figuras retóricas son técnicas típicas de la narración oral y en el cuento "Clemencia bajo el sol" no parecen artificiales porque considerando el carácter del personaje Cuqui y su contexto socio-económico -es vendedora ambulante con pocos ingresos- se preserva el aptum de su discurso. Aunque Cuqui confiesa haber matado a una mujer, no desiste del derecho de contar su versión de la historia: "Ya estoy condenada, déjeme hablar, hablar hasta por los codos y las rodillas, que buena falta me hace" (Fernández de Juan, 2002, p. 77). Este texto pertenece al grupo que arriba he denominado "diálogo con un interlocutor callado". En esta estructura narratológica, Cuqui, la protagonista y narradora autodiegética, habla en forma de un diálogo, pero las palabras del interlocutor, en este caso el juez a quien Cuqui se dirige con las formas de tratamiento "usted" y "señor", solo son reproducidas por la protagonista. Las preguntas y las llamadas al orden judiciales tienen la intención de encauzar las explicaciones de Cuqui y darles coherencia, de frenar sus divagaciones y limitar su relato.

De vez en cuando la protagonista no entiende las inserciones por parte del juez y se defiende contra este discurso dominante:

¿Qué eso no tiene relación con la occisa? ¿Qué occisa? ¡Ah, la muerta! Pero, por favor, déjeme hablar, claro que
tiene relación mi historia con esa puta que maté sin querer. Tenga paciencia, ya me declaré culpable, escúchame y
que todos me oigan también, a ver si de alguna manera nos limpiamos un poco (Fernández de Juan, 2002, p. 78).

Las dificultades en la comunicación entre Cuqui, el sujeto subalterno, y el juez, representante del poder hegemónico, parecen muy obvias en estos tres pasajes citados. Las exclamaciones de la protagonista-narradora "no voy a bajar la voz", "déjeme hablar" (2x) y "escúchame y que todos me oigan también" manifiestan cierta resistencia contra las

26 De paso sea mencionado que este cuento de Fernández de Juan constituye uno de los pocos textos que tematizan las relaciones entre cubanos y rusos. Notablemente, los lazos amistosos entre Cuba y la Unión Soviética no tienen importancia para la cultura cubana contemporánea. En su ensayo "Lo que dejaron los rusos" (2004b), el escritor cubano José Miguel Sánchez (Yoss) (2004b, p. 138) expresa esta orientación de la siguiente manera: "Es sorprendente; treinta años de presencia rusa en esta isla no dejaron casi nada, aparte de unos cuantos edificios horribles". 
limitaciones, las mutilaciones, el silenciamiento impuestos por parte del poder y una voluntad de expresarse por parte de ella misma.

\section{5. ¿Personajes, constelaciones y escritores subalternos?}

En los últimos años, el discurso postrevolucionario y distópico, la poética del desencanto, así como la tendencia hacia lo grotesco, lo absurdo y el nihilismo de la cuentística cubana contemporánea han sido ampliamente comentados por el mundo académico (por ejemplo: Behar, 2009; Casamayor-Cisneros, 2013; Fornet, 2006; Garrandés, 2005; López Sacha, 2006; Mateo Palmer, 2005; Rubio Cuevas, 2001; Uxó, 2010; Whitfield, 2008). Estas observaciones suelen apoyarse en el análisis de las transformaciones en la concepción de personajes. En las décadas de los 60, 70 y en gran parte de los 80, los autores solían concebir personajes literarios que se identificaban con el proyecto revolucionario, personajes que formaban parte de la sociedad revolucionaria impulsados por su propia decisión o convicción. El cuento "El lobo, el bosque y el hombre nuevo" de Senel Paz, conocido a nivel mundial por la adaptación cinematográfica Fresa y Chocolate (1993) de los directores cubanos Tomás Gutiérrez Alea y Juan Carlos Tabío, es tal vez uno de los últimos ejemplos literarios de tal creación de personajes. Es un cuento sobre la amistad entre el protagonista-narrador David, estudiante universitario y miembro de la Unión de Jóvenes Comunistas, y Diego, un artista disidente y homosexual que decide abandonar su patria. En el transcurso de la historia, David, el revolucionario por convicción, intenta convencer a Diego de permanecer en Cuba pues opina que la sociedad, aunque no perfecta, es justa y reformable.

En los noventa, por lo general, este tipo de personaje revolucionario apenas sirve de blanco para la crítica satírica por parte de los escritores o directores de cine, por ejemplo, si uno piensa en el papel de Adolfo, un burócrata de la vieja escuela, en la película Guantanamera (1995). En los textos de los novísimos narradores el ideal del "hombre nuevo" deja de existir. Aquí abundan personajes decepcionados, desilusionados, solitarios, marginados y rebeldes como criminales, prostitutas, jóvenes rockeros o soldados internacionalistas de la Guerra de Angola. Ya no hay espacio para discursos utópicos, los personajes e instancias narrativas intentan buscar en repetidas ocasiones "la verdad" mediante reflexiones personales; sin embargo, están condenados a no encontrar respuestas a sus preguntas éticas, filosóficas, antropológicas o sociales. En este caso, los cuentos se caracterizan por la duda, el pesimismo y la agresividad de las reflexiones, sobre todo en la forma de un cinismo cáustico al describir las diferencias económicas y culturales entre los cubanos y los turistas extranjeros, como se aprecia en los cuentos "Fallen Angels" de Joel Cano, "No hay regreso para Johnny" de David Mitrani o "La causa que refresca" de José Miguel Sánchez (Yoss).

Al aplicar la dicotomía hegemonía y subalternidad a aquellos cuentos que retratan las repercusiones del turismo en la antigua "perla del Caribe", podemos identificar una constelación de "actantes" (Greimas, 1966, pp. 172-191) bien marcada: las fisuras sociales no aparecen como fenómeno interno de la sociedad insular, más bien las diferencias entre pobres y ricos se ilustran a través de la confrontación entre cubanos y viajeros extranjeros. El gran ausente en la lucha contra la pobreza es el gobierno y sus instituciones. Al contrario, los representantes estatales como los jueces o los policías son retratados negativamente, dado que dificultan e impiden las iniciativas ilegales o semilegales (mercado negro, jineterismo, 
cuentapropismo, etc.) de los marginados para salir de la miseria. Así, en los cuentos de mi corpus aparece, por un lado, una hegemonía política en su manifestación jurídica y ejecutiva que está asociada con el poder estatal (véase líneas arriba el análisis de "Clemencia bajo el sol" de Adelaida Fernández de Juan) y, por otro, una hegemonía económica relacionada con los turistas (como en "Relato de hombre al margen" de Alberto Garrido, mencionado en el segundo apartado).

¿Y cómo se sitúan los escritores en este contexto? En siete cuentos del corpus, los autores tienen el papel protagónico en la historia narrada e introducen al lector en el ámbito literario cubano marcado por los problemas elementales de sobrevivencia y el afán estético de hablar sobre la realidad circundante. Los textos "El muro de las lamentaciones" y "Relato de hombre al margen" de Alberto Garrido describen el transcurso del día de los protagonistasescritores que están confrontados con distintas formas de marginalidad. Mientras "El viejo, el asesino y yo" de Ena Lucía Portela tematiza los conflictos entre distintas generaciones de autores. Los protagonistas-narradores de los cuentos "Tocata y fuga en cuatro movimientos y tres reposos" de Ronaldo Menéndez y "Los heraldos negros" de Alberto Guerra Naranjo reflejan cómo plasman en papel los acontecimientos a los que asistieron. En los cuentos "Yo, revolcador de mierda" de Pedro Juan Gutiérrez y "Finca Vigía" de Alberto Guerra Naranjo, se dedica una parte importante de los textos a las discusiones sobre la poética y el mercado literario dentro y fuera de Cuba.

De tal manera, estos siete cuentos reflejan debates en torno a escritores reales. Según Salvador Redonet (1999), los jóvenes narradores cubanos de los noventa se encuentran en un constante diálogo con la realidad circundante. Uxó (2010, p. 193) sigue las pautas de Redonet al comentar que ellos crean mundos polífonos en contraposición a la verdad única del canon establecido y considera que "es precisamente esta perspectiva autoral problematizadora, transgresora y marcadamente iconoclasta la nota más característica y distintiva de la literatura de los Novísimos". Sin duda, el iconoclasmo temático, una nueva autodefinición de escritor y cierta voluntad testimonial son los rasgos característicos de la cuentística finisecular. La narrativa revolucionaria de los 60 y 70 miraba hacia el pasado, sobre todo hacia la dictadura de Batista, la lucha guerrillera y las transformaciones políticas y sociales memorables que tuvieron lugar con el triunfo de la Revolución Cubana en el año 1959; en cambio, la cuentística a partir de los ochenta se concentra más en la vida cotidiana inmediata. El entorno social en la última década del siglo XX estuvo marcado por la crisis económica, la depauperación y la pérdida de las utopías políticas. Para el crítico literario y escritor Alberto Garrandés (2005, p. 285), la "sobreabundancia de lo real" determina el estilo de sus coetáneos que cultivan tradiciones realistas, vanguardistas, neobarrocas y postmodernas. Junto a razones poetológicas, la voluntad testimonial tiene otras causas: muchos de los autores contemporáneos se autodefinen como "conciencia crítica de la tragicomedia cotidiana" (Garrandés, 2005, p. 299) y redactan narraciones ligadas al mundo real, dado que los medios de comunicación estatales están censurados en su tarea de informar sobre la realidad cubana. En este contexto, las descripciones literarias de la decadencia económica, social y moral durante los noventa pueden ser interpretadas también como crítica hacia un sistema que permite tal situación. Finalmente, hay que añadir que el mercado internacional estuvo sumamente interesado en textos que retraten la miseria en el socialismo tropical. La marginalidad, la decadencia, un marcado exotismo sensual y una crítica hacia el régimen político fomentaron el boom de la 
literatura cubana en el extranjero (Fornet, 2006, pp. 96-102; Rössner, 2002, pp. 516-517; Rubio Cuevas, 2001; Whitfield, 2008).

¿Entonces, lo subalterno es solo una forma de costumbrismo literario y al fin de cuentas una estrategia de marketing? Sonia Behar refuta esta tesis argumentando que el escritor cubano está fuertemente enraizado en la realidad circundante y "expresa su protesta personal contra el entorno, actuando a la vez como vocero de sus personajes" (Behar, 2009, p. 68). El análisis de este doble acto de enunciación, o sea, el autor que articula su protesta personal (= nivel de la realidad) y actúa como vocero de sus personajes (= nivel de la ficcionalidad), queda como desideratum. Para un análisis profundo del aspecto real, se tendría que indagar lo que los autores en forma de ensayos, paratextos o entrevistas pronuncian sobre su propia obra literaria (véase, por ejemplo, el documental La Habana escrita de Gustavo Gil, 2002) y, en el caso de que se acepte el concepto de implied author (Booth, 1961, p. 71), se debería incluir esta entidad en el análisis. Ante un corpus de 120 cuentos y con el espacio limitado de este artículo, me he enfocado únicamente en el aspecto ficcional de esta cuestión (temas, voces narrativas, lenguaje, personajes, constelaciones).

Resumiendo, los escritores cubanos, a causa de distintos motivos, reaccionaron rápidamente ante las malas condiciones de vida durante el Período Especial y retrataron la nueva pobreza mediante un modo ficcional. La miseria económica constituye uno de los temas centrales de la cuentística cubana finisecular, además es una pobreza general, como indican los textos del corpus en los cuales deambulan frecuentemente personajes afectados por la penuria cotidiana, desde mendigos hasta universitarios. Particularmente interesantes para la cuestión de la articulación subalterna son aquellos siete cuentos en que los autores figuran como protagonistas de la historia narrada. No se trata de "intelectuales orgánicos" gramscianos, puesto que su pensamiento y actitud no tienen un pronunciado carácter político-clasista, ni tampoco son meros ecos del habla subalterna, una de las reivindicaciones de Spivak, más bien los autores-protagonistas observan con cierta distancia las transformaciones profundas de índole socio-económico e ideológico por las cuales ellos mismos también son afectados. Los autores-protagonistas pobres, al igual que otros sujetos subalternos ficcionales, no se limitan a ser víctimas, sino que, como se aprecia en un número notable de cuentos, luchan para deshacerse del estatus subalterno y toman la palabra en forma de discurso de personaje o de instancia narrativa. Los resultados del análisis temático-narratológico cuantitativo muestran que de mi corpus de 120 cuentos, 59 textos contienen descripciones de pobreza. Entre estos 59 cuentos hay 29 que utilizan instancias narrativas homodiegéticas, de las cuales 18 viven en condiciones miserables; 23 cuentos se caracterizan por instancias narrativas heterodiegéticas, pero en solo dos textos los lectores se encuentran frente a una focalización interna que se encuadra dentro de una perspectiva subalterna. De los siete relatos que oscilan entre instancias narrativas homodiegéticas y heterodiegéticas, tenemos igualmente en tres textos narradores pobres. En suma, en 21 (o 23 si incluimos los dos cuentos con instancia heterogénea y focalización interna) de los 59 textos, la articulación subalterna se realiza en el marco de la ficción literaria, esto es en más de un tercio de los cuentos con descripciones de pobreza. Mediante estas voces subalternas textuales los lectores pueden formarse una idea de lo que significa vivir en la pobreza. 


\section{Bibliografía}

Abreu Morales, A. (1997). Lección I. En A. Garrandés (Ed.). Poco antes del 2000: Jóvenes cuentistas cubanos en las puertas del nuevo siglo (pp. 51-55). La Habana: Letras Cubanas.

Acanda, J. L. et al. (1997). Releyendo a Gramsci: hegemonía y sociedad civil. Temas, 10, 75-86. Recuperado de http://temas.cult.cu/sites/default/files/articulos_academicos_en_pdf/ Descargar\%20art\%C3\%ADculo\%20en_153.pdf

Achúgar, W., Felsberg, U., González Macho, E., Herrero, G., Núñez, A., y Vives, C. (Productores), Gutiérrez Alea, T. y Tabío, J. C. (Directores). (1995). Guantanamera. [Película]. Alemania, Cuba, España: Alta Films, Dritte Produktion, ICAIC, Road Movies y Tornasol Films.

Alonso, N. (1997a). Falsos profetas. En N. Alonso. Tirar la primera piedra (pp. 44-61). La Habana: Letras Cubanas.

Alonso, N. (1997b). Tirar la primera piedra. En N. Alonso. Tirar la primera piedra (pp. 7-14). La Habana: Letras Cubanas.

Arango, A. (2004). Lista de espera. En A. Garrandés (Ed.). Aire de luz: Cuentos cubanos del siglo $X X$ (2 ed.) (pp. 405-428). La Habana: Letras Cubanas.

Arzola, J. L. (1993). Prisioneros en el círculo del horizonte. En S. Redonet (Ed.). Los últimos serán los primeros (pp. 159-170). La Habana: Letras Cubanas.

Arzola, J. L. (1997). Ruinas. En A. Garrandés (Ed.). Poco antes del 2000: Jóvenes cuentistas cubanos en las puertas del nuevo siglo (pp. 26-28). La Habana: Letras Cubanas.

Arzola, J. L. (2000). La banda infinita. En J. L. Arzola. La banda infinita (pp. 37-48). La Habana: Letras Cubanas.

Ashcroft, B., Griffiths, G. y Tiffin, H. (1998). Key Concepts in Post-Colonial Studies. London/ New York: Routledge.

Bahr, A. (2000). Olor a limón. En M. Yáñez (Ed.). Habaneras: Diez narradoras cubanas (pp. 77-89). Tafalla: Txalaparta.

Balzaretti, G., Cabrera, F., Cobo, N., González, J., Muñoz, J., Urra, L. y Vives, C. (Productores) y Gutiérrez Alea, T. y Tabío, J. C. (Directores). (1993). Fresa y Chocolate. [Película]. Cuba, España, México: ICAIC, IMCINE, Tabasco Films, Telemadrid y SGAE.

Barfuss, T. y Jehle, P. (2014). Antonio Gramsci zur Einführung. Hamburg: Junius.

Barthes, R. (1968). L'effet de réel. Communications, 11, 84-89.

Behar, S. (2009). La caída del Hombre Nuevo: Narrativa cubana del Período Especial. New York et al.: Peter Lang.

Beverley, J. (1999). Subalternity and Representation. Arguments in Cultural Theory. Durham/ London: Duke University Press.

Bobes, M. (1995). Pregúntaselo a Dios. En M. Bobes. Alguien tiene que llorar (pp. 61-69). La Habana: Casa de las Américas. 
Bobes, M. (2000). En Florencia diez años después. En M. Yáñez (Ed.). Habaneras: Diez narradoras cubanas (pp. 61-67). Tafalla: Txalaparta.

Booth, W. C. (1961). The Rhetoric of Fiction. Chicago/London: University of Chicago Press.

Cano, J. (2002). Fallen Angels. En M. Strausfeld (Ed.). Nuevos narradores cubanos (2 ed.) (pp. 161-185). Madrid: Siruela.

Casamayor-Cisneros, O. (2013). Utopía, distopía e ingravidez: Reconfiguraciones cosmológicas en la narrativa postsoviética cubana. Madrid/Frankfurt am Main: Iberoamericana/ Vervuert.

Castro Varela, M. y Dhawan, N. (2015). Postkoloniale Theorie. Eine kritische Einführung (2 ed.). Bielefeld: Transcript.

Chanan, M. (2001). Cuba and Civil Society, or Why Cuban Intellectuals Are Talking about Gramsci. Nepantla: Views from South, 2(2), 387-406.

Collazo, M. (1996). Un asunto de altura en el Niágara. En F. López Sacha (Ed.). La Isla contada: El cuento contemporáneo en Cuba (2 ed.) (pp. 171-192). Donostia: Tercera Prensa-Hirugarren Prentsa.

Díaz Llanillo, E. (2000). El gran golpe. En M. Yáñez (Ed.). Habaneras: Diez narradoras cubanas (pp. 23-25). Tafalla: Txalaparta.

Díaz Mantilla, D. (1993). el punk. En S. Redonet (Ed.). Los últimos serán los primeros (pp. 234-241). La Habana: Letras Cubanas.

Díaz-Pimienta, A. (2002). La guagua. En M. Strausfeld (Ed.). Nuevos narradores cubanos (2 ed.) (pp. 157-160). Madrid: Siruela.

Ebenhoch, M. (2013). Representaciones de la pobreza en la cuentística cubana finisecular. En C. Reverte Bernal (Ed.). Actas del XXXIX Congreso del Instituto Internacional de Literatura Iberoamericana (Cádiz 2012) (pp. 1183-1192). Madrid: Editorial Verbum.

Fernández de Juan, A. (2002). Clemencia bajo el sol. En M. Strausfeld (Ed.). Nuevos narradores cubanos (2 ed.) (pp. 77-85). Madrid: Siruela.

Fornet, J. (2006). Los nuevos paradigmas: Prólogo narrativo al siglo XXI. La Habana: Letras Cubanas.

Foucault, M. (1971). L'Ordre du discours. Paris: Gallimard.

Foucault, M. (1994). Dits et Écrits. Paris: Gallimard.

Gala, M. (1997). Anoche, mientras estabas afuera. En A. Garrandés (Ed.). Poco antes del 2000: Jóvenes cuentistas cubanos en las puertas del nuevo siglo (pp. 46-50). La Habana: Letras Cubanas.

Gala, M. (2004). La violencia de las horas. En A. Garrandés (Ed.). Aire de luz: Cuentos cubanos del siglo XX (2 ed.) (pp. 527-537). La Habana: Letras Cubanas.

Garrandés, A. (1997). Fábula de un amor feliz. En A. Garrandés (Ed.). Poco antes del 2000: Jóvenes cuentistas cubanos en las puertas del nuevo siglo (pp. 56-71). La Habana: Letras Cubanas. 
Garrandés, A. (2005). Presunciones. La Habana: Letras Cubanas.

Garrido, A. (1999a). El muro de las lamentaciones. En A. Garrido. El muro de las lamentaciones (pp. 11-27). La Habana: Casa de las Américas.

Garrido, A. (1999b). Relato de hombre al margen. En A. Garrido. El muro de las lamentaciones (pp. 83-102). La Habana: Casa de las Américas.

Garrido, A. (2002). Diana cazadora and Colorado Springs. En M. Strausfeld (Ed.). Nuevos narradores cubanos (2 ed.) (pp. 213-222). Madrid: Siruela.

Garrido, A. (2004). Los tejedores de Anna Welsel. En A. Garrandés (Ed.). Aire de luz: Cuentos cubanos del siglo XX (2 ed.) (pp. 468-472). La Habana: Letras Cubanas.

Garrido Rodríguez, A. (1993). Desde el jardín. En S. Redonet (Ed.). Los últimos serán los primeros (pp. 179-185) La Habana: Letras Cubanas.

Gil, G. (Productor y director). (2002). La Habana escrita. [Película]. s.l.: s.n.

Gramsci, A. (1975). Quaderni del carcere. (vol. 3). (Ed. V. Gerratana). Torino: Giulio Einaudi.

Greaney, P. (2008). Untimely Beggar: Poverty and Power from Baudelaire to Benjamin. Minneapolis/London: University of Minnesota Press.

Greimas, A. J. (1966). Sémantique structurale. Recherche de méthode. Paris: Larousse.

Guerra Naranjo, A. (2002a). Corazón partido bajo otra circunstancia. En M. Strausfeld (Ed.). Nuevos narradores cubanos (2 ed.) (pp. 53-75). Madrid: Siruela.

Guerra Naranjo, A. (2002b). Finca Vigía. En A. Guerra Naranjo. Blasfemia del escriba (2 ed.) (pp. 9-30). La Habana: Letras Cubanas.

Guerra Naranjo, A. (2002c). Los heraldos negros. En A. Guerra Naranjo. Blasfemia del escriba (2 ed.) (pp. 163-179). La Habana: Letras Cubanas.

Guerra Naranjo, A. (2002d). Otra vez Arnaldo. En A. Guerra Naranjo. Blasfemia del escriba (2 ed.) (pp. 31-43). La Habana: Letras Cubanas.

Gutiérrez, P. J. (2001a). Los caníbales. En P. J. Gutiérrez. Trilogía sucia de La Habana (7 ed.) (pp. 324-331). Barcelona: Anagrama.

Gutiérrez, P. J. (2001b). Yo, revolcador de mierda. En P. J. Gutiérrez. Trilogía sucia de La Habana (7 ed.) (pp. 101-105). Barcelona: Anagrama.

Haug, S. (2003). Piedad. En J. Shor (Ed.). Nueva narrativa cubana (pp. 37-47). Santiago de Chile: RIL.

Huertas Uhagón, B. (1993). Ensayo de un cambio: La narrativa cubana de los '80. La Habana: Casa de las Américas.

Jesús, P. (2002). El retrato. En M. Strausfeld (Ed.). Nuevos narradores cubanos (2 ed.) (pp. 251-270). Madrid: Siruela.

Kayser, W. (1971). Das sprachliche Kunstwerk: Eine Einführung in die Literaturwissenschaft. Bern/München: Francke.

Llano, E. (2002). Greenpeace. En M. Strausfeld (Ed.). Nuevos narradores cubanos (2 ed.) (pp. 107-118). Madrid: Siruela. 
Llano, E. (2004). Las treinta monedas de la Virgen. En A. Garrandés (Ed.). Aire de luz: Cuentos cubanos del siglo XX (2 ed.) (pp. 584-591). La Habana: Letras Cubanas.

López Sacha, F. (2002). Dorado mundo. En F. López Sacha. Dorado mundo (2 ed.) (pp. 55-72). La Habana: Letras Cubanas.

López Sacha, F. (2006). Pastel 'flameante'. La Habana: Letras Cubanas.

Mateo Palmer, M. (2005). Ella escribía poscrítica (2 ed.) La Habana: Letras Cubanas.

Martín Sevillano, A. B. (2004). Cuento cubano actual (1985-2000). (Tesis doctoral). Universidad Complutense de Madrid, España.

Martínez Heredia, F. (2001). Gramsci in 1960s Cuba. Nepantla: Views from South, 2(2), 373-385.

Mejides, M. (2004). Rumba Palace. En A. Garrandés (Ed.). Aire de luz: Cuentos cubanos del siglo XX (2 ed.) (pp. 429-441). La Habana: Letras Cubanas.

Menéndez, R. (1993). Tocata y fuga en cuatro movimientos y tres reposos. En S. Redonet (Ed.). Los últimos serán los primeros (pp. 228-233). La Habana: Letras Cubanas.

Menéndez, R. (2002). La verticalidad de las cosas. En M. Strausfeld (Ed.). Nuevos narradores cubanos (2 ed.) (pp. 279-297). Madrid: Siruela.

Mitrani, D. (2002). No hay regreso para Johnny. En M. Strausfeld (Ed.). Nuevos narradores cubanos (2 ed.) (pp. 141-156). Madrid: Siruela.

Morton, S. (2003). Gayatri Chakravorty Spivak. London/New York: Routledge.

Nandi, M. (2007). M/Other India/s: Zur literarischen Verarbeitung von Armuts- und Kastenproblematik in ausgewählten Texten der indisch-englischen und muttersprachlichen indischen Literatur seit 1935. Heidelberg: Universitätsverlag Winter.

Noemi Voionmaa, D. (2003). Estética de la pobreza en la literatura latinoamericana. (Tesis doctoral). Yale University, Estados Unidos.

Padura, L. (1996). El cazador. En F. López Sacha(Ed.). La Isla contada: El cuento contemporáneo en Cuba (2 ed.) (pp. 139-154). Donostia: Tercera Prensa-Hirugarren Prentsa.

Paz, S. (2004). El lobo, el bosque y el hombre nuevo. En A. Garrandés (Ed.). Aire de luz: Cuentos cubanos del siglo XX (2 ed.) (pp. 442-464). La Habana: Letras Cubanas.

Palacio Rame, E. M. (1993). El amor oscuro. En S. Redonet (Ed.). Los últimos serán los primeros (pp. 195-206). La Habana: Letras Cubanas.

Perdomo, M. (1997). Los amantes de Konarak. En A. Garrandés (Ed.). Poco antes del 2000: Jóvenes cuentistas cubanos en las puertas del nuevo siglo (pp. 81-89). La Habana: Letras Cubanas.

Pérez, N. (2003). Josiane. En J. Shor (Ed.). Nueva narrativa cubana (pp. 21-35). Santiago de Chile: RIL.

Ponte, A. J. (2002). Un arte de hacer ruinas. En M. Strausfeld (Ed.). Nuevos narradores cubanos (2 ed.) (pp. 123-139). Madrid: Siruela.

Portela, E. L. (1993). La urna y el nombre (Un cuento jovial). En S. Redonet (Ed.). Los últimos serán los primeros (pp. 261-269). La Habana: Letras Cubanas. 
Portela, E. L. (2002). El viejo, el asesino y yo. En M. Strausfeld (Ed.). Nuevos narradores cubanos (2 ed.) (pp. 313-334). Madrid: Siruela.

Quintana Veiga, J. A. (2006). Mi amor y mi caña. En H. Arango (Ed.). Maneras de narrar: Cuentos del Premio La Gaceta de Cuba (1993-2005) (pp. 85-101). La Habana: Unión.

Redonet, S. (1999). Bis repetita placent (Palimpsesto). En S. Redonet (Ed.). Para el siglo que viene: (Post)novísimos narradores cubanos (pp. 9-23). Zaragoza: Prensas Universitarias de Zaragoza.

Ribeaux, A. (1997). Les Demoiselles d'Avignon. En A. Garrandés (Ed.). Poco antes del 2000: Jóvenes cuentistas cubanos en las puertas del nuevo siglo (pp. 103-107). La Habana: Letras Cubanas.

Robles, A. (2006). Los muertos. En H. Arango (Ed.). Maneras de narrar: Cuentos del Premio La Gaceta de Cuba (1993-2005) (pp. 41-52). La Habana: Unión.

Rodríguez, M. A. (2006). En la Tierra de la Reina Maud. En H. Arango (Ed.). Maneras de narrar: Cuentos del Premio La Gaceta de Cuba (1993-2005) (pp. 53-61). La Habana: Unión.

Rössner, M. (Ed.). (2002). Lateinamerikanische Literaturgeschichte (2 ed.). Stuttgart/Weimar: Metzler.

Rubio Cuevas, I. (2001). La doble insularidad de los novísimos narradores cubanos. En C. Allemany Bay, R. Mataix Azuar y J. C. Rovira Soler (Eds.). La isla posible: III Congreso de la Asociación Española de Estudios Literarios Hispanoamericanos (pp. 547-554). Alicante: Biblioteca Virtual Miguel de Cervantes.

Sánchez, J. M. (Yoss). (2002). La causa que refresca. En M. Strausfeld (Ed.). Nuevos narradores cubanos (2 ed.) (pp. 245-250). Madrid: Siruela.

Sánchez, J. M. (Yoss). (2004a). Hermes. En A. Garrandés (Ed.). Aire de luz: Cuentos cubanos del siglo XX (2 ed.) (pp. 544-561). La Habana: Letras Cubanas.

Sánchez, J. M. (Yoss). (2004b). Lo que dejaron los rusos. Temas, 37-38, 138-144.

Santiesteban, Á. (2002). Lobos en la noche. En M. Strausfeld (Ed.). Nuevos narradores cubanos (2 ed.) (pp. 191-203). Madrid: Siruela.

Spivak, G. C. (1987). In other Worlds. Essays in Cultural Politics. New York/London: Methuen.

Spivak, G. C. (1988). Can the Subaltern Speak? En C. Nelson y L. Grossberg (Eds.). Marxism and the Interpretation of Culture (pp. 271-313). Houndmills/London: MacMillan Education.

Spivak, G. C. (1990). The Post-Colonial Critic: Interview, Strategies, Dialogues. (Ed. S. Harasym). New York/London: Routledge.

Spivak, G. C. (1996). The Spivak Reader: Selected Works of Gayatri Chakravorty Spivak. (Eds. D. Landry y G. MacLean). New York/London: Routledge.

Spivak, G. C. (1999). A Critique of Postcolonial Reason: Toward a History of the Vanishing Present. Cambridge (Massachusetts)/London: Harvard University Press.

Torralbas Caurel, J. M. (1993). Último tren a Londres. En S. Redonet (Ed.). Los últimos serán los primeros (pp. 90-97). La Habana: Letras Cubanas. 
Uxó, C. (2010). Los Novísimos cubanos: primera generación de escritores nacidos en la Revolución. Letras Hispánicas, 7, 186-198. Recuperado de http:/gato-docs.its.txstate.edu/

Valdés, Z. (2002). Retrato de una infancia habanaviejera. En M. Strausfeld (Ed.). Nuevos narradores cubanos (2 ed.) (pp. 17-24). Madrid: Siruela.

Valle, A. (2004). Mambrú no fue a la guerra. En A. Garrandés (Ed.). Aire de luz: Cuentos cubanos del siglo XX (2 ed.) (pp. 506-522). La Habana: Letras Cubanas.

Valle Ojeda, A. (1993). Miedo. En S. Redonet (Ed.). Los últimos serán los primeros (pp. 195197). La Habana: Letras Cubanas.

Vega, A. L. (2002). Esperando a Elio. En M. Strausfeld (Ed.). Nuevos narradores cubanos (2 ed.) (pp. 223-231). Madrid: Siruela.

Vega Serova, A. L. (1998). Erre con erre. En A. L. Vega Serova. Catálogo de mascotas (pp. 99-115). La Habana: Letras Cubanas.

Venero, A. (2003). Luces. En J. Shor (Ed.). Nueva narrativa cubana (pp. 49-58). Santiago de Chile: RIL.

White, H. (1973). Metahistory. The Historical Imagination in Nineteenth-Century Europe. Baltimore/London: Johns Hopkins UP.

Whitfield, E. (2008). Cuban Currency: The Dollar and "Special Period” Fiction. Minneapolis/ London: University of Minnesota Press.

\section{Anexo}

Corpus

El corpus está constituido por 120 cuentos escritos por narradores cubanos entre 1990 y 2000. La mayoría de los autores de los cuentos analizados vivieron y viven en la isla; sin embargo, se han incluido también en este estudio a escritores que durante los noventa se decidieron por el exilio y otros que oscilan entre Cuba y el exterior. Muchos de los cuentos recibieron prestigiosos premios internacionales, por ejemplo, el Premio Juan Rulfo (Paris) y el Premio Casa de las Américas (La Habana) o premios nacionales como el de La Gaceta de Cuba. El equilibrio con respecto al lugar de la publicación es otro criterio para delimitar el corpus, por tal motivo los textos escogidos provienen asimismo de cinco antologías cubanas y cinco antologías publicadas fuera de la isla, respectivamente. Los 59 cuentos que contienen representaciones de la pobreza están marcados con asteriscos.

Abreu Arcia, Alberto. "Memorias de un regaño", in: Redonet, Salvador (Ed.). Los últimos serán los primeros. La Habana: Letras Cubanas, 1993, 72-75.

*Abreu Morales, Armando. "Lección I", in: Garrandés, Alberto (Ed.). poco antes del 2000: Jóvenes cuentistas cubanos en las puertas del nuevo siglo. La Habana: Letras Cubanas, 1997, 51-55.

Aguiar, Raúl. "Apoptosis", in: Redonet, Salvador (Ed.). El ánfora del diablo: Novísimos cuentistas cubanas. La Habana: Extramuros, 1999, 22-28.

Aguiar Álvarez, Raúl. “Aquiel”, in: Redonet, Salvador (Ed.). Los últimos serán los primeros. La Habana: Letras Cubanas, 1993, 98-111. 
Aguiar, Raúl. "Hoguera”, in: Garrandés, Alberto (Ed.). Aire de luz: Cuentos Cubanos del Siglo XX. La Habana: Letras Cubanas, 2004, 538-543.

Aguilera, Carlos A. "Cronología”, in: Redonet, Salvador (Ed.). El ánfora del diablo: Novísimos cuentistas cubanas. La Habana: Extramuros, 1999, 38-44.

*Alonso, Nancy. "Falsos profetas”, in: Alonso, Nancy. Tirar la primera piedra. La Habana: Letras Cubanas, 1997, 44-61.

*Alonso, Nancy. "Tirar la primera piedra", in: Alonso, Nancy. Tirar la primera piedra. La Habana: Letras Cubanas, 1997, 7-14.

*Arango, Arturo. "Lista de espera", in: Garrandés, Alberto (Ed.) Aire de luz: Cuentos cubanos del siglo XX. La Habana: Letras Cubanas, ${ }^{2} 2004,405-428$.

Arrieta, Ricardo. "La horma”, in: Redonet, Salvador (Ed.). Los últimos serán los primeros. La Habana: Letras Cubanas, 1993, 186-194.

Arrieta, Ricardo. "Una ficción más auténtica que la realidad dulce de canabis", in: Redonet, Salvador (Ed.). El ánfora del diablo: Novísimos cuentistas cubanas. La Habana: Extramuros, 1999, 12-16.

*Arzola, Jorge Luis. "La banda infinita", in: Arzola, Jorge Luis. La banda infinita. La Habana: Letras Cubanas, 2000, 37-48.

*Arzola, Jorge Luis. "Prisioneros en el círculo del horizonte”, in: Redonet, Salvador (Ed.). Los últimos serán los primeros. La Habana: Letras Cubanas, 1993, 159-170.

*Arzola, Jorge Luis. "Ruinas", in: Garrandés, Alberto (Ed.). poco antes del 2000: Jóvenes cuentistas cubanos en las puertas del nuevo siglo. La Habana: Letras Cubanas, 1997, 26-28.

Bahr, Aida. "Imperfecciones", in: López Sacha, Francisco (Ed.): La Isla contada: El cuento contemporáneo en Cuba. Donostia: Tercera Prensa-Hirugarren Prentsa, 1996, 101-104.

*Bahr, Aida. "Olor a limón”, in: Yáñez, Mirta (Ed.). Habaneras: Diez narradoras cubanas. Tafalla: Txalaparta, 2000, 77-89.

Bobes, Marilyn. “Alguien tiene que llorar”, in: Bobes, Marilyn. Alguien tiene que llorar. La Habana: Casa de las Américas, 1995, 7-24.

*Bobes, Marilyn. “En Florencia diez años después”, in: Yáñez, Mirta (Ed.). Habaneras: Diez narradoras cubanas. Tafalla: Txalaparta, 2000, 61-67.

Bobes, Marilyn. "Esta vez tienes que hacerme caso", in: Bobes, Marilyn. Alguien tiene que llorar. La Habana: Casa de las Américas, 1995, 33-43.

*Bobes, Marilyn. "Pregúntaselo a Dios" in: Bobes, Marilyn. Alguien tiene que llorar. La Habana: Casa de las Américas, 1995, 61-69.

Bobes, Marilyn. “'Te gusta Peter Handke?”, in: Bobes, Marilyn. Alguien tiene que llorar. La Habana: Casa de las Américas, 1995, 25-32.

Boudet, Rosa Ileana. "Postales a la manga”, in: Yáñez, Mirta (Ed.). Habaneras: Diez narradoras cubanas. Tafalla: Txalaparta, 2000, 99-116.

Caballero, Atilio. "De rerum novarum", in: Garrandés, Alberto (Ed.). poco antes del 2000: Jóvenes cuentistas cubanos en las puertas del nuevo siglo. La Habana: Letras Cubanas, 1997, 72-78. 
Calcines, Carlo. "Informe”, in: Redonet, Salvador (Ed.). Los últimos serán los primeros. La Habana: Letras Cubanas, 1993, 152-155.

*Cano, Joel. "Fallen Angels", in: Strausfeld, Michi (Ed.) Nuevos narradores cubanos. Madrid: Siruela, 2002, 161-185.

*Collazo, Miguel. “Un asunto de altura en el Niágara”, in: López Sacha, Francisco (Ed.): La Isla contada: El cuento contemporáneo en Cuba. Donostia: Tercera Prensa-Hirugarren Prentsa, 1996, 171-192.

Casanova Rivera, Omar. "El butacón", in: Redonet, Salvador (Ed.). Los últimos serán los primeros. La Habana: Letras Cubanas, 1993, 57-60.

Curbelo, Jesús David. “Alta traición”, in: Curbelo, Jesús David. Cuentos para adúlteros. La Habana: Letras Cubanas, 1997, 63-83.

*Díaz Llanillo, Ester. "El gran golpe”, in: Yáñez, Mirta (Ed.). Habaneras: Diez narradoras cubanas. Tafalla: Txalaparta, 2000, 23-25.

*Díaz Mantilla, Daniel. “el punk”, in: Redonet, Salvador (Ed.). Los últimos serán los primeros. La Habana: Letras Cubanas, 1993, 234-241.

Díaz Mantilla, Daniel. "La puerta”, in: Redonet, Salvador (Ed.). El ánfora del diablo: Novísimos cuentistas cubanas. La Habana: Extramuros, 1999, 46-49.

Díaz Mantilla, Daniel. “Una semana de clases”, in: Garrandés, Alberto (Ed.). poco antes del 2000: Jóvenes cuentistas cubanos en las puertas del nuevo siglo. La Habana: Letras Cubanas, 1997, 37-45.

Díaz Pimienta, Alexis. "Cosas de este mundo o La Muchacha de la Calle Tirry”, in: Garrandés, Alberto (Ed.). poco antes del 2000: Jóvenes cuentistas cubanos en las puertas del nuevo siglo. La Habana: Letras Cubanas, 1997, 30-36.

*Díaz-Pimienta, Alexis. "La guagua”, in: Strausfeld, Michi (Ed.) Nuevos narradores cubanos. Madrid: Siruela, 2002, 157-160.

*Fernández de Juan, Adelaida. "Clemencia bajo el sol”, in: Strausfeld, Michi (Ed.) Nuevos narradores cubanos. Madrid: Siruela, 2002, 77-85.

Fernández Pintado, Mylene. "El día que no fui a Nueva York", in: Strausfeld, Michi (Ed.) Nuevos narradores cubanos. Madrid: Siruela, 2002, 119-122.

*Gala, Marcial. "Anoche, mientras estabas afuera”, in: Garrandés, Alberto (Ed.). poco antes del 2000: Jóvenes cuentistas cubanos en las puertas del nuevo siglo. La Habana: Letras Cubanas, 1997, 46-50.

*Gala, Marcial. "La violencia de las horas”, in: Garrandés, Alberto (Ed.). Aire de luz: Cuentos cubanos del siglo XX. La Habana: Letras Cubanas, 2004, 527-537.

Galiano, Alfredo. "Cuando saltes el muro", in: Garrandés, Alberto (Ed.). poco antes del 2000: Jóvenes cuentistas cubanos en las puertas del nuevo siglo. La Habana: Letras Cubanas, 1997, 98-102.

Galiano Rodríguez, Alfredo. "Regino en dos actos”, in: Redonet, Salvador (Ed.). Los últimos serán los primeros. La Habana: Letras Cubanas, 1993, 207-212.

García Calzada, Ana Luz. "Los convidados”, in: Yáñez, Mirta (Ed.). Habaneras: Diez narradoras cubanas. Tafalla: Txalaparta, 2000, 91-98. 
*Garrandés, Alberto. "Fábula de un amor feliz", in: Garrandés, Alberto (Ed.). poco antes del 2000: Jóvenes cuentistas cubanos en las puertas del nuevo siglo. La Habana: Letras Cubanas, 1997, 56-71.

Garrandés, Alberto. "Isabeau”, in: Garrandés, Alberto (Ed.) Aire de luz: Cuentos cubanos del siglo XX. La Habana: Letras Cubanas, 2004, 483-496.

Garrandés, Alberto. "Kermesse”, in: Redonet, Salvador (Ed.). Los últimos serán los primeros. La Habana: Letras Cubanas, 1993, 48-56.

*Garrido Rodríguez, Alberto. “Desde el jardín”, in: Redonet, Salvador (Ed.). Los últimos serán los primeros. La Habana: Letras Cubanas, 1993, 179-185.

*Garrido, Alberto. "Diana cazadora and Colorado Springs", in: Strausfeld, Michi (Ed.) Nuevos narradores cubanos. Madrid: Siruela, 2002, 213-222.

Garrido, Alberto. “El brazo y el lienzo”, in: López Sacha, Francisco (Ed.): La Isla contada: El cuento contemporáneo en Cuba. Donostia: Tercera Prensa-Hirugarren Prentsa, 1996, 205-210.

*Garrido, Alberto. "El muro de las lamentaciones", in: Garrido, Alberto. El muro de las lamentaciones. La Habana: Casa de las Américas, 1999, 11-27.

Garrido, Alberto. "En el vórtice”, in: Arango, Haydée (Ed.) Maneras de narrar: Cuentos del Premio La Gaceta de Cuba (1993-2005). La Habana: Unión, 2006, 31-37.

*Garrido, Alberto. "Los tejedores de Anna Welsel”, in: Garrandés, Alberto (Ed.) Aire de luz: Cuentos cubanos del siglo XX. La Habana: Letras Cubanas, 2004, 468-472.

*Garrido, Alberto. "Relato de hombre al margen", in: Garrido, Alberto. El muro de las lamentaciones. La Habana: Casa de las Américas, 1999, 83-102.

González, Andrés Jorge. "El canto de las sirenas”, in: Redonet, Salvador (Ed.). Los últimos serán los primeros. La Habana: Letras Cubanas, 1993, 61-71.

*Guerra Naranjo, Alberto. "Corazón partido bajo otra circunstancia” in: Strausfeld, Michi (Ed.) Nuevos narradores cubanos. Madrid: Siruela, 2002, 53-75.

Guerra Naranjo, Alberto. "Cuesta abajo”, in: Guerra Naranjo, Alberto. Blasfemia del escriba. La Habana: Letras Cubanas, 2002, 151-162.

*Guerra Naranjo, Alberto. "Finca Vigía”, in: Guerra Naranjo, Alberto. Blasfemia del escriba. La Habana: Letras Cubanas, 2002, 9-30.

*Guerra Naranjo, Alberto. "Los heraldos negros", in: Guerra Naranjo, Alberto. Blasfemia del escriba. La Habana: Letras Cubanas, 2002, 163-179.

*Guerra Naranjo, Alberto. "Otra vez Arnaldo", in: Guerra Naranjo, Alberto. Blasfemia del escriba. La Habana: Letras Cubanas, 2002, 31-43.

*Gutiérrez, Pedro Juan. "Los caníbales", in: Gutiérrez, Pedro Juan. Trilogía sucia de La Habana. Barcelona: Anagrama, 2001, 324-331.

*Gutiérrez, Pedro Juan. "Yo, revolcador de mierda”, in: Gutiérrez, Pedro Juan. Trilogía sucia de La Habana. Barcelona: Anagrama, 2001, 101-105.

*Haug, Susana. "Piedad", in: Shor, Jacqueline (Ed.). Nueva narrativa cubana. Santiago de Chile: RIL, 2003, 37-47.

Henríquez Lagarde, Manuel. "La escampada", in: Redonet, Salvador (Ed.). Los últimos serán los primeros. La Habana: Letras Cubanas, 1993, 128-137. 
*Jesús, Pedro de. "El retrato", in: Strausfeld, Michi (Ed.) Nuevos narradores cubanos. Madrid: Siruela, 2002, 251-270.

León, José Félix. "Narciso y un espejo”, in: Arango, Haydée (Ed.) Maneras de narrar: Cuentos del Premio La Gaceta de Cuba (1993-2005). La Habana: Unión, 2006, 191-197.

Lizárraga, Félix. "Las aguas del abismo", in: Strausfeld, Michi (Ed.) Nuevos narradores cubanos. Madrid: Siruela, 2002, 41-47.

Llana, María Elena. "Mariposas de noviembre”, in: Yáñez, Mirta (Ed.). Habaneras: Diez narradoras cubanas. Tafalla: Txalaparta, 2000, 69-75.

*Llano, Eduardo del. "Greenpeace”, in: Strausfeld, Michi (Ed.) Nuevos narradores cubanos. Madrid: Siruela, 2002, 107-118.

*Llano, Eduardo del. "Las treinta monedas de la Virgen”, in: Garrandés, Alberto (Ed.). Aire de luz: Cuentos cubanos del siglo XX. La Habana: Letras Cubanas, 2004, 584-591.

López Sacha, Francisco. "Con el rostro pintado de un salvaje”, in: López Sacha, Francisco. Dorado mundo. La Habana: Letras Cubanas, 2002, 51-54.

*López Sacha, Francisco. "Dorado mundo”, in: López Sacha, Francisco. Dorado mundo. La Habana: Letras Cubanas, 2002, 55-72.

Martín, Rita. "Elisa o el precio del sueño", in: Redonet, Salvador (Ed.). Los últimos serán los primeros. La Habana: Letras Cubanas, 1993, 138-143.

*Mejides, Miguel. "Rumba Palace”, in Garrandés, Alberto (Ed.). Aire de luz: Cuentos cubanos del siglo XX. La Habana: Letras Cubanas, 2004, 429-441.

Mendoza Quevedo, Karina. “Las señales y la flauta”, in: Redonet, Salvador (Ed.). Los últimos serán los primeros. La Habana: Letras Cubanas, 1993, 242-260.

Menéndez Plasencia, Ronaldo. "El jugador: prolegómenos para una lectura del sentido”, in: Redonet, Salvador (Ed.). El ánfora del diablo: Novísimos cuentistas cubanas. La Habana: Extramuros, 1999, 29-33.

*Menéndez, Ronaldo. "La verticalidad de las cosas", in: Strausfeld, Michi (Ed.) Nuevos narradores cubanos. Madrid: Siruela, 2002, 279-297.

*Menéndez, Ronaldo. "Tocata y fuga en cuatro movimientos y tres reposos", in: Redonet, Salvador (Ed.). Los últimos serán los primeros. La Habana: Letras Cubanas, 1993, 228-233.

*Mitrani, David. "No hay regreso para Johnny", in: Strausfeld, Michi (Ed.) Nuevos narradores cubanos. Madrid: Siruela, 2002, 141-156.

*Padura, Leonardo. "El cazador", in: López Sacha, Francisco (Ed.): La Isla contada: El cuento contemporáneo en Cuba. Donostia: Tercera Prensa-Hirugarren Prentsa, 1996, 139-154.

Paz, Senel. "El lobo, el bosque y el hombre nuevo", in: Garrandés, Alberto (Ed.) Aire de luz: Cuentos Cubanos del Siglo XX. La Habana: Letras Cubanas, 2004, 442-464.

*Palacio Rame, Elena María. "El amor oscuro”, in: Redonet, Salvador (Ed.). Los últimos serán los primeros. La Habana: Letras Cubanas, 1993, 195-206.

*Perdomo, Michel. "Los amantes de Konarak", in: Garrandés, Alberto (Ed.). poco antes del 2000: Jóvenes cuentistas cubanos en las puertas del nuevo siglo. La Habana: Letras Cubanas, 1997, 81-89. 
*Pérez, Nelton. "Josiane", in: Shor, Jacqueline (Ed.). Nueva narrativa cubana. Santiago de Chile: RIL, 2003, 21-35.

Pérez Cino, Waldo. "La reja”, in: Strausfeld, Michi (Ed.) Nuevos narradores cubanos. Madrid: Siruela, 2002, 299-311.

Pérez Cino, Waldo. “Los gemelos”, in: Garrandés, Alberto (Ed.). poco antes del 2000: Jóvenes cuentistas cubanos en las puertas del nuevo siglo. La Habana: Letras Cubanas, 1997, 108-114.

Pérez Konina, Verónica. "Ernesto II", in: Redonet, Salvador (Ed.). Los últimos serán los primeros. La Habana: Letras Cubanas, 1993, 216-219.

Picart Baluja, Gina. "La poza del ángel”, in: Garrandés, Alberto (Ed.) Aire de luz: Cuentos Cubanos del Siglo XX. La Habana: Letras Cubanas, 2004, 600-604.

*Ponte, Antonio José. “Un arte de hacer ruinas”, in: Strausfeld, Michi (Ed.) Nuevos narradores cubanos. Madrid: Siruela, 2002, 123-139.

Portela, Ena Lucía. "El viejo, el asesino y yo", in: Strausfeld, Michi (Ed.) Nuevos narradores cubanos. Madrid: Siruela, 2002, 313-334.

*Portela, Ena Lucía. “La urna y el nombre (Un cuento jovial)”, in: Redonet, Salvador (Ed.). Los últimos serán los primeros. La Habana: Letras Cubanas, 1993, 261-269.

Portela, Ena Lucía. “Sombrio despertar del avestruz”, in: Redonet, Salvador (Ed.). El ánfora del diablo: Novísimos cuentistas cubanas. La Habana: Extramuros, 1999, 52-63.

Prieto, José Manuel. “El tartamudo y la rusa”, in: Strausfeld, Michi (Ed.) Nuevos narradores cubanos. Madrid: Siruela, 2002, 87-106.

*Quintana Veiga, José Antonio. “Mi amor y mi caña”, in: Arango, Haydée (Ed.) Maneras de narrar: Cuentos del Premio La Gaceta de Cuba (1993-2005). La Habana: Unión, 2006, 85-101.

*Ribeaux, Ariel. “Les Demoiselles d'Avignon”, in: Garrandés, Alberto (Ed.). poco antes del 2000: Jóvenes cuentistas cubanos en las puertas del nuevo siglo. La Habana: Letras Cubanas, 1997, 103-107.

Risco, Enrique del. "El predestinado", in: Garrandés, Alberto (Ed.). poco antes del 2000: Jóvenes cuentistas cubanos en las puertas del nuevo siglo. La Habana: Letras Cubanas, 1997, 79-80.

Riverón Morales, Rogelio. “Ah, la piedad”, in: Garrandés, Alberto (Ed.). poco antes del 2000: Jóvenes cuentistas cubanos en las puertas del nuevo siglo. La Habana: Letras Cubanas, 1997, 122-124.

Riverón Morales, Rogelio. "El hombre que quería subir al cielo", in: Redonet, Salvador (Ed.). Los últimos serán los primeros. La Habana: Letras Cubanas, 1993, 144-148.

*Robles, Alejandro. "Los muertos", in: Arango, Haydée (Ed.) Maneras de narrar: Cuentos del Premio La Gaceta de Cuba (1993-2005). La Habana: Unión, 2006, 41-52.

*Rodríguez, Manuel Antonio. "En la Tierra de la Reina Maud”, in: Arango, Haydée (Ed.) Maneras de narrar: Cuentos del Premio La Gaceta de Cuba (1993-2005). La Habana: Unión, 2006, 53-61.

Rodríguez Tosca, Alberto. "Miguel”, in: Redonet, Salvador (Ed.). Los últimos serán los primeros. La Habana: Letras Cubanas, 1993, 83-89. 
*Sánchez, José Miguel (Yoss). "Hermes”, in: Garrandés, Alberto (Ed.) Aire de luz: Cuentos cubanos del siglo XX. La Habana: Letras Cubanas, 2004, 544-561.

*Sánchez, José Miguel (Yoss). "La causa que refresca”, in: Strausfeld, Michi (Ed.) Nuevos narradores cubanos. Madrid: Siruela, 2002, 245-250.

Sánchez, José Miguel (Yoss). "Rufus el suicida”, in: Redonet, Salvador (Ed.). Los últimos serán los primeros. La Habana: Letras Cubanas, 1993, 222-227.

Sánchez Mejías, Rolando. "Escrituras”, in: Redonet, Salvador (Ed.). Los últimos serán los primeros. La Habana: Letras Cubanas, 1993, 37-44.

Sánchez Mejías, Rolando. "La noche del mundo”, in: López Sacha, Francisco (Ed.): La Isla contada: El cuento contemporáneo en Cuba. Donostia: Tercera Prensa-Hirugarren Prentsa, 1996, 211-220.

Santana, Ernesto. "Historia de unos ojos y una voz", in: Garrandés, Alberto (Ed.). poco antes del 2000: Jóvenes cuentistas cubanos en las puertas del nuevo siglo. La Habana: Letras Cubanas, 1997, 115-121.

Santiesteban, Ángel. "Después del silencio”, in: Garrandés, Alberto (Ed.). poco antes del 2000: Jóvenes cuentistas cubanos en las puertas del nuevo siglo. La Habana: Letras Cubanas, 1997, 90-96.

Santiesteban Prats, Ángel. "La misión", in: Santiesteban Prats, Ángel. Sur: latitud 13. Barcelona: Emily, 2005, 54-61.

*Santiesteban, Ángel. "Lobos en la noche", in: Strausfeld, Michi (Ed.) Nuevos narradores cubanos. Madrid: Siruela, 2002, 191-203.

Santiesteban Prats, Ángel. "Mambrú no fue a la guerra", in: Santiesteban Prats, Ángel. Sur: latitud 13. Barcelona: Emily, 2005, 96-103.

Saunders, Rogelio. "El mediodía del bufón”, in: Redonet, Salvador (Ed.). Los últimos serán los primeros. La Habana: Letras Cubanas, 1993, 115-127.

Suárez, Karla. “Un poema para Alicia”, in: Strausfeld, Michi (Ed.) Nuevos narradores cubanos. Madrid: Siruela, 2002, 233-244.

*Torralbas Caurel, José Mariano. "Último tren a Londres", in: Redonet, Salvador (Ed.). Los últimos serán los primeros. La Habana: Letras Cubanas, 1993, 90-97.

*Valdés, Zoé. "Retrato de una infancia habanaviejera", in: Strausfeld, Michi (Ed.) Nuevos narradores cubanos. Madrid: Siruela, 2002, 17-24.

*Valle, Amir. "Mambrú no fue a la guerra”, in: Garrandés, Alberto (Ed.) Aire de luz: Cuentos cubanos del siglo XX. La Habana: Letras Cubanas, 2004, 506-522.

*Valle Ojeda, Amir. "Miedo", in: Redonet, Salvador (Ed.). Los últimos serán los primeros. La Habana: Letras Cubanas, 1993, 195-197.

Vega, Anna Lidia. “Collage con fotos y danzas”, in: Alcántara, Marco (Ed.). Cuentos hispanoamericanos: Cuba. Erzählungen aus Cuba. München: dtv, 2005, 34-50.

*Vega Serova, Anna Lidia. “Erre con erre”, in: Vega Serova, Anna Lidia. Catálogo de mascotas. La Habana: Letras Cubanas, 1998, 99-115.

*Vega, An[n]a Lidia. "Esperando a Elio", in: Strausfeld, Michi (Ed.) Nuevos narradores cubanos. Madrid: Siruela, 2002, 223-231. 
Vega Serova, Anna Lidia. "Naturaleza muerta con hierba”, in: Vega Serova, Anna Lidia. Bad painting. La Habana: Unión, 1998, 7-12.

*Venero, Alicio. "Luces", in: Shor, Jacqueline (Ed.). Nueva narrativa cubana. Santiago de Chile: RIL, 2003, 49-58.

Yáñez, Mirta. “Cortados en dos”, in: Yáñez, Mirta (Ed.). Habaneras: Diez narradoras cubanas. Tafalla: Txalaparta, 2000, 27-33. 